Published in final edited form as:

Surg Oncol Clin N Am. 2014 April ; 23(2): 231-246. doi:10.1016/j.soc.2013.10.004.

\title{
Intrahepatic Cholangiocarcinoma
}

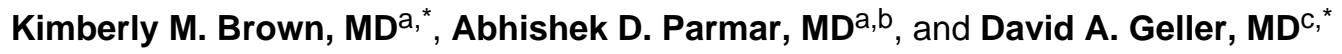 \\ aDepartment of Surgery, University of Texas Medical Branch, 301 University Boulevard, \\ Galveston, TX 77555-0541, USA \\ bDepartment of Surgery, University of California San Francisco-East Bay, 1411 East 31st Street, \\ Oakland, CA 94602, USA \\ 'Liver Cancer Center, University of Pittsburgh School of Medicine, 3459 Fifth Avenue, Pittsburgh, \\ PA 15213-2582, USA
}

\section{Keywords}

Intrahepatic cholangiocarcinoma; Peripheral cholangiocarcinoma; Cholangiocarcinoma; Bile duct neoplasms; Intrahepatic bile duct cancer

\section{INTRODUCTION: NATURE OF THE PROBLEM}

\section{Epidemiology}

Intrahepatic cholangiocarcinoma (ICC) is a subtype of a family of aggressive cholangiocarcinomas, tumors that arise from cholangiocytes of the biliary tree. There are several key epidemiologic considerations of ICC:

- ICCs are rare, accounting for $20 \%$ to $25 \%$ of all cholangiocarcinomas; perihilar $(50 \%-60 \%)$ or distal common bile duct $(20 \%-25 \%)$ tumors are more common (Fig. 1). ${ }^{1}$ They are still the second most common primary liver malignancy, following hepatocellular carcinoma. ${ }^{2}$

- The incidence rate of ICCs for Americans has increased from 3.2 per 1,000,000 in 1975 to 1979 to 8.5 per $1,000,000$ in 1995 to $1999,3,4$ but this trend has stabilized over the last decade. ${ }^{5}$

- The reasons underlying this increasing incidence are unclear, but potential reasons include changes in the classification system ${ }^{6}$ or a recent increase in the incidence of Hepatitis C. $^{7}$ This increased incidence does not seem to be related to increased tumor detection, as there has been no change in the proportion of early stage or smaller tumors detected over time. ${ }^{3}$

- Population-based data demonstrate that men are 1.5 times as likely to develop ICCs as women in the United States.

(C) 2014 Elsevier Inc. All rights reserved.

Corresponding authors.km3brown@utmb.edu; gellerda@upmc.edu.

Disclosures: None. 
- The average age of diagnosis worldwide is 50 years old, and patients are rarely diagnosed younger than age $40.3,8$

- ICCs are lethal malignancies with more aggressive tumor biology than the more common liver malignancy, hepatocellular carcinoma. ${ }^{9}$ Overall 3-year and 5-year survival rates are a dismal $30 \%$ and $18 \%$, respectively. ${ }^{10}$

- Mortality from ICCs has risen over the last several decades. Data from the World Health Organization database indicate that although mortality has improved for extrahepatic biliary tumors, mortality has actually increased worldwide for ICCs since the 1970s. ${ }^{11}$ For the United States, age-adjusted mortality has risen from 0.7 per 1,000,000 in 1973 to 6.9 per 1,000,000 in 1997, paralleling the rising incidence of ICCs (Fig. 2). ${ }^{4}$

\section{Risk Factors}

Risk factors for ICC can range from established precursors such as choledochal cysts, cholangitis, and toxin exposure to potential associations such as smoking and diabetes. ${ }^{12}$ Patients with chronic inflammatory processes such as primary sclerosing cholangitis and patients infected with the parasites Opisthorchis viverrini or Clonorchis sinensis are at particularly increased risk for ICC. ${ }^{13}$ Other risk factors are listed in Box 1. Although these factors are key considerations in the diagnosis of ICC, most of these cancers occur de novo in the absence of any underlying liver disease. ${ }^{7,14}$

\section{Box 1}

\section{Risk factors for cholangiocarcinoma}

\section{Established risk factors}

Primary sclerosing cholangitis

Choledochal cyst

Parasitic infection (Opisthorchis viverrini or Clonorchis sinensis)

Inflammatory bowel disease

Drug or toxin exposure (thorotrast)

Biliary cirrhosis

Cholelithiasis

Bile duct adenoma and biliary papillomatosis

Alcoholic liver disease

\section{Associated risk factors}

Diabetes

Thyrotoxicosis

Chronic pancreatitis 
Obesity

Nonalcoholic liver disease

Hepatitis $\mathrm{B} / \mathrm{C}$ infection

Typhoid

Smoking

\section{Subtypes}

The Liver Cancer Study Group of Japan has distinguished 3 different histologic subtypes of ICCs: mass-forming, periductal infiltrating, and intraductal growth (Fig. 3). ${ }^{15}$

- Mass-forming ICCs are the most common and are characteristically solid nodules that are discrete from the surrounding liver parenchyma. Intrahepatic metastases are more commonly observed with this subtype. ${ }^{16}$

- Periductal infiltrating ICCs invade the liver parenchyma along portal structures and metastasize to hilar lymph nodes; this subtype rarely forms a discrete liver mass. A combined mass-forming-periductal-infiltrating tumor type is an aggressive subtype correlating with decreased survival in the Japanese series, ${ }^{17,18}$ but this finding has not been observed in Western populations. ${ }^{19}$

- Intraductal growth ICCs are the least common subtype and can be characterized by growth into the biliary tract lumen. These ICCS may represent less aggressive variants with a more favorable prognosis. ${ }^{20}$

\section{CLINICAL PRESENTATION AND DIAGNOSIS}

\section{Clinical Presentation}

The clinical presentation of ICCs is usually nonspecific, and symptoms can include generalized abdominal pain, or less commonly, weight loss and jaundice.

- In a retrospective review of a 31-year experience at Johns Hopkins University, patients with ICC most commonly presented with abdominal pain and were less likely to experience jaundice or weight loss than patients with extrahepatic cholangiocarcinoma. ${ }^{21}$ This finding was confirmed in other studies. ${ }^{22,23}$

- Because these tumors are discrete from the main bile ducts and rarely cause obstructive jaundice, clinical diagnoses are rare, and many patients initially present with advanced disease. ${ }^{13,24}$ In addition, incidental diagnoses of ICCs in asymptomatic patients are also relatively common, accounting for $12 \%$ to $30 \%$ of diagnoses in some series. ${ }^{14,25}$

- A single-institution retrospective review at the Memorial Sloan Kettering Cancer Center demonstrated that $54 \%$ of these tumors are unresectable at presentation. ${ }^{23}$ 


\section{Diagnosis and Initial Evaluation}

The nonspecific, aggressive presentation of ICC, coupled with its relatively rare incidence, makes the initial diagnosis challenging. ICCs are most commonly identified on crosssectional imaging, which is also used for staging and determining tumor resectability. Determining the diagnosis before intervention has significant treatment implications given the unique tumor biology of these cancers relative to others (hepatocellular carcinoma, metastatic adenocarcinoma). Laboratory tests are rarely helpful, with occasional exceptions:

- CA 19-9 is the most widely used laboratory test, but it is nonspecific and may be elevated in any number of benign or malignant diseases. ${ }^{26,27}$ It may serve a role as an ancillary test in patients with PSC who present with a suspicious intrahepatic lesion. In these patients a value greater than $100 \mathrm{U} / \mathrm{mL}$ carries a sensitivity and specificity of $89 \%$ and $86 \%$, respectively, for the diagnosis of cholangiocarcinoma. ${ }^{28}$

- a-Fetoprotein is similarly controversial and has been suggested to play a role in differentiating ICCs from hepatocellular carcinoma. ${ }^{29}$ In one study by Koh and colleagues ${ }^{9}$ these values were typically lower or normal in patients with ICCs compared with patients with hepatocellular carcinoma, but this finding was not statistically significant.

- On ultrasound there are no characteristic findings to differentiate these lesions from secondary metastases or hepatocellular carcinoma. ${ }^{30,31}$

- Cross-sectional imaging with computed tomography (CT) or magnetic resonance imaging (MRI) rarely identifies any pathognomonic features of ICC compared with other liver lesions. As a result, neither is superiorto the other in the initial diagnosis of these tumors. ${ }^{32}$ However, there are findings on these studies that can aid in the diagnosis, particularly when the 2 modalities are used in conjunction.

- Characteristic findings of ICC on CT include the following:

- Thin rimlike contrast enhancement on both arterial and portal venous phases;

- Areas of low attenuation within the tumor with areas of high attenuation scattered throughout, also on both phases ${ }^{33}$;

- Delayed contrast enhancement, which may also correlate with poor prognosis. In a retrospective comparison of patients with tumors with delayed contrast enhancement versus those without enhancement, patients in the former group experienced worse overall survival. ${ }^{34}$

- Characteristic findings of ICC on MRI include the following:

- Hypointensity on T1-weighted imaging and hyperintensity on T2weighted imaging;

- Peripheral enhancement, progressive concentric filling, and contrast pooling on delayed images in contrast-enhanced MRI. ${ }^{29}$ 
- The utility of PET-CT in the initial diagnosis and staging of suspected ICC is unclear. Studies have been mixed, with some finding a sensitivity and specificity greater than $85 \%,{ }^{35,36}$ whereas others observed limited specificity in the presence of infectious or inflammatory processes. 37,38

- Patients who present with a hepatic lesion, biopsy-proven to be adenocarcinoma with an unknown primarylesion, represent special diagnostic cases. In these patients the aim is to discern primary ICC from secondary metastases, and patients should undergo a thorough evaluation to identify a potential primary lesion. These evaluations should include cross-sectional imaging of the chest, abdomen, and pelvis, upper and lower endoscopy, mammography, and gynecologic evaluation as indicated.

\section{STAGING AND PROGNOSIS}

\section{7th Edition AJCC Staging}

Previous iterations of the American Joint Committee on Cancer (AJCC) staging for ICCs had been based on data from patients with hepatocellular carcinoma. Findings from population-based studies ${ }^{5}$ and basic science literature ${ }^{39,40}$ have demonstrated that ICCs are pathologic entities with a more aggressive tumor biology and distinct phenotype than hepatocellular carcinoma. Recognizing this, Nathan and colleagues ${ }^{10}$ used Surveillance, Epidemiology, and End Results-Medicare data from 1988 to 2004 to (1) assess the validity of the 6th edition staging system and (2) identify prognostic findings from pathologically confirmed ICCs. The authors observed that tumor size as defined by the previous staging classification had no prognostic value, whereas vascular invasion, number of tumors, and extent of lymph node invasion had significant prognostic significance. Based on these findings, the AJCC revised the previous classification system to construct the 7th edition staging classification, the first novel staging system for patients with ICCs (Table 1). ${ }^{41}$

- In a multi-institutional study of 12 tertiary academic centers, the AFC-IHCC-2009 study group validated the AJCC 7th edition staging classification as a discriminatory system in which each TNM stage was associated with significantly varying survival outcomes (Fig. 4). ${ }^{42}$

- Another single-institutional Japanese study recognized in a multivariate analysis that this system has some limitations and ignores or underestimates the influence of tumor histology and multiplicity while overemphasizing the influence of periductal invasion. ${ }^{43}$

- Wang and colleagues ${ }^{44}$ conducted a multivariate analysis to construct a prognostic nomogram for overall 3-year and 5-year survival. This study confirmed the prognostic implications of tumor multiplicity, vascular invasion, and lymphatic spread, all of which are included in the current AJCC staging system. However, in this retrospective review the addition of carcinoembryonic antigen (CEA) and CA 19-9 levels resulted in improved staging accuracy. 


\section{MANAGEMENT AND TREATMENT}

Although there have been some developments in adjuvant therapies, surgical resection remains the only potentially curative treatment modality for patients with ICCs. ${ }^{21,45,46}$ This section deals with the considerations of operative resection, including the extent of resection, minimally invasive surgical techniques, and orthotopic liver transplantation (OLT). Finally, the role of other nonsurgical therapies is discussed.

\section{Preoperative Preparation}

The preoperative evaluation of a patient with suspected ICC should include high-quality cross-sectional imaging of the liver to determine tumor resectability but should also include a detailed evaluation to exclude metastatic or occult primary disease in the chest, abdomen, and pelvis. A discussion of all of the considerations involved in hepatic parenchymal resection is outside the scope of this article, but a few salient points are mentioned:

- Resectability in ICC is defined as the ability to resect tumor to negative margins while preserving adequate functioning liver with intact arterial, portal venous, and hepatic venous flow, and biliary-enteric drainage.

- Preservation of an adequate functioning liver is a central tenet in liver surgery but predicting the amount and function of viable future liver remnant is sometimes difficult. Most authors have suggested $20 \%$ to $25 \%$ of future liver remnant ${ }^{47-49}$ or $40 \%$ future liver remnant in patients with compromised liver function ${ }^{50}$ as standard cutoff values.

- Preoperative portal venous embolization has been developed as a technique to stimulate hypertrophy in the future liver remnant by interrupting flow to tumorbearing segments, thereby mitigating the risks of postoperative liver failure. The data on this technique in patients with ICCs are limited but studies in other populations have demonstrated that it is safe and can reduce the incidence of postoperative liver failure. ${ }^{50,51}$

\section{Staging Laparoscopy}

Staging laparoscopy has been demonstrated to reduce unnecessary laparotomy for patients with hepatopancreaticobiliary malignancies. However, in the largest series of staging laparoscopy for ICC (53 patients), the sensitivity of staging laparoscopy was only $55 \% .{ }^{52} \mathrm{~A}$ smaller study of 11 patients also demonstrated a high false-negative rate with laparoscopy for ICCs, but this finding is inconclusive given the small sample size. ${ }^{53}$ Unresectability is often determined by local involvement of vascular supply or biliary drainage of the future liver remnant, which may not be evident on laparoscopic exploration, contributing to the low yield for laparoscopy. As a result, routine staging laparoscopy is not currently recommended in these patients.

\section{Hepatic Resection}

- Morbidity and mortality after hepatectomy have declined over the past several decades, owing to improved surgical technique, perioperative care, and advances in 
hemostasis. ${ }^{54}$ For ICCs, perioperative morbidity and mortality range from $1 \%$ to $14 \%{ }^{21,23,25,52,55-59}$ and $6 \%$ to $43 \%,{ }^{21,23,25,52,55-59}$ respectively. Studies of survival after resection and factors associated with survival are illustrated in Table 2.

- $\quad \mathrm{R} 0$ resection (resection of both gross and microscopic disease) is the aim of curative intent surgery 60 and is associated with favorable outcomes, ${ }^{19,21,22,25,52,58,60,61}$ but is achieved in only $45 \%$ to $96 \%$ of attempted resections. ${ }^{19,21-23,25,52,55-57,60,61}$

- $\quad$ R0 resection only improves survival in cases where regional lymphatic spread has not already occurred and has been confirmed in 2 multi-institutional studies. ${ }^{19,60}$

- Five-year overall survivals after resection range from $17 \%$ to $44 \%$, with median survivals of 12 to 43 months. ${ }^{19,21,23,25,55,57,59,62}$

\section{Lymphadenectomy}

The lymphatic drainage of the liver is generally predictable, and the left lobe of the liver generally drains toward the lesser curve and cardia of the stomach, whereas the right lobe drains to the hepatoduodenal ligament. ${ }^{63}$ However, for ICC there are some important considerations with regards to lymph node disease:

- In a study mapping the lymphatic drainage of patients with left-sided ICC, $46 \%$ of tumor deposits were identified in the hepatoduodenal ligament, where right-sided tumor metastases normally occur. ${ }^{64}$

- Although lymphatic involvement is a clear prognostic factor, there is no evidence that routine lymphadenectomy confers any survival benefit. ${ }^{65}$ Although this finding has been observed in only small single-institution studies, most large series demonstrate that routine lymphadenectomy is rarely performed in practice. ${ }^{19,23,52,57}$

- Lymphadenectomy with surgical resection is recommended in patients with grossly positive lymphatic disease, but spread beyond the regional lymph node basins is a contraindication to resection. 66

\section{Vascular Resection}

- Because ICCs are locally invasive tumors, vascular invasion is a relatively common occurrence, and vascular resections are required in $9 \%$ to $14 \%$ of hepatectomies. $^{23,25,52,55,57,58,61}$

- Vascular resection is feasible in experienced centers. In a single-institution review by the Mayo Clinic, $12 \%$ of patients underwent major vascular resection. ${ }^{55}$ There was no difference in achievable $\mathrm{R} 0$ resections in patients who required vascular resection compared with patients who did not require vascular resection. In addition, there were no differences in perioperative morbidity and mortality. As a result, overall 5-year survival did not differ between groups (44\% in the vascular resection group vs $23 \%$ in the nonresected group, $P=.268$ ). 


\section{Minimally Invasive Surgery}

Since the advent of minimally invasive surgical techniques for hepatic resection in the early 1990s, many of the initial questions of the feasibility of minimally invasive hepatic resection have been answered. Although there have been no randomized controlled trials comparing minimally invasive liver resection to open techniques, there are several observational studies that support the use of the minimally invasive approach. ${ }^{67}$

- Minimally invasive hepatic resection is associated with decreased narcotic pain medication requirement, decreased hospital length of stay, and comparable morbidity and mortality when compared with open resection. ${ }^{68-71}$

- In small case-control series of patients with hepatic malignancy, minimally invasive hepatectomy was not associated with margin positivity or decreased disease-free survival. ${ }^{70,72}$ However, the conclusions of these observational studies should be approached with caution as they are subject to selection bias. Prospective studies are needed to determine the true impact of minimally invasive techniques on the adequacy of hepatic resection for patients with cancer.

- Robotic resections of hepatic malignancies are currently being investigated with promising results, ${ }^{73-75}$ but long-term data are lacking and these resections should only be undertaken at high-volume centers with specialized expertise in robotic surgery.

\section{Transplant}

Given the locally aggressive nature of ICCs, OLT has been attempted as a treatment option. Potential indications for OLT in this population include locally advanced unresectable disease or the presence of advanced cirrhosis that would preclude partial hepatectomy.

- In one of the earliest experiences with OLT for ICC at the University of Pittsburgh, investigators observed similar tumor-free survival and recurrence rates in a small retrospective series $(\mathrm{N}=54)$ of patients who underwent hepatectomy versus OLT. ${ }^{76}$

- However, similar patterns in disease-free survival have not been consistently reproduced. Other experiences with OLT have found dismally low disease-free survival rates of $40 \%$ at 1 year, ${ }^{77}$ or high recurrence rates of $51 \%$ to $80 \%{ }^{78,79}$ The University of California, Los Angeles OLT experience for ICCs actually observed a trend toward improved recurrence-free survival with OLT compared with hepatectomy. ${ }^{80}$

- In a retrospective review of United Network for Organ Sharing database from 1987 to 2005, 1-year and 5-year survival for 280 patients who underwent OLT for ICCs were $74 \%$ and $38 \%$, respectively. ${ }^{81}$

- Nearly all of these studies included some form of adjuvant or neoadjuvant therapy in conjunction with OLT. Based on these mixed data and the potential likelihood for high tumor recurrence in patients with ICCs, OLT for ICC should only be considered in the context of clinical trials. 
- Noteworthy, the Mayo Clinic team has reported excellent results with OLT for early-stage Klaskin cholangiocarcinoma tumors, typically in the setting of PSC, with 5-year OS rate of $\sim 70 \% .{ }^{82}$

\section{Medical Therapy}

Nonsurgical therapies for ICCs have not been demonstrated to improve survival or decrease recurrence independently. Because of the relative rarity of ICCs, data on chemotherapy in the adjuvant setting are lacking, but chemotherapy may serve a role in select populations:

- For patients with unresectable ICCs, combination chemotherapy with cisplatin and gemcitabine may provide a survival benefit. In a prospective randomized controlled trial of unresectable biliary tract cancers, Valle and colleagues ${ }^{83}$ observed a modest survival benefit ( $\sim 3$ months) with combined cisplatin-gemcitabine therapy compared with gemcitabine alone. In a subgroup analysis of patients with ICC, patients treated with combination therapy experienced a survival benefit (hazard ratio [HR] for mortality $0.57,95 \% \mathrm{CI} 0.34-0.94)$.

- Studies of other adjuvant therapies have been limited by small sample size or retrospective design.

- Radiation therapy in conjunction with surgery was suggested to improve survival when compared with resection alone in a retrospective population-based study, ${ }^{84}$ but this observation is subject to unmeasured confounding and should be interpreted with caution.

- Transarterial chemoembolization (TACE) is a promising therapy with limited side effects $^{85}$ that may improve survival in patients with unresectable ICC. ${ }^{86}$ In one nonrandomized study, treatment with gemcitabine-cisplatin combination TACE resulted in significantly longer survival (13.8 months) compared with TACE with gemcitabine alone (6.3 months). ${ }^{87}$ TACE has had limited impact in the adjuvant setting. ${ }^{88}$

\section{SUMMARY}

ICCs are aggressive malignancies that have been increasing in incidence and mortality over time. Few patients present with resectable disease at the time of presentation, and diagnosis is often difficult because of the occult nature and anatomic position of ICCs. Prognostic features, such as multifocality, vascular invasion, lymphatic spread, and histopathology, should be considered in the management and treatment of these patients. However, because of the relative rarity of ICCs, little is known of the optimal treatment strategy beyond surgical resection. Prospective data are needed to better characterize the efficacy of minimally invasive techniques, transplantation, chemotherapeutic regimens, and other adjuvant therapies on patients who present with this lethal disease.

\section{Acknowledgments}

Funding: Supported by grants from the UTMB Clinical and Translational Science Award no. UL1TR000071 and NIH T-32 Grant no. 5T32DK007639. 


\section{References}

1. Khan SA, Davidson BR, Goldin R, et al. Guidelines for the diagnosis and treatment of cholangiocarcinoma: consensus document. Gut. 2002; 51(Suppl 6):VI1-9. [PubMed: 12376491]

2. Khan SA, Toledano MB, Taylor-Robinson SD. Epidemiology, risk factors, and pathogenesis of cholangiocarcinoma. HPB (Oxford). 2008; 10(2):77-82. [PubMed: 18773060]

3. Shaib Y, El-Serag HB. The epidemiology of cholangiocarcinoma. Semin Liver Dis. 2004; 24(2): 115-25. [PubMed: 15192785]

4. Patel T. Increasing incidence and mortality of primary intrahepatic cholangiocarcinoma in the United States. Hepatology. 2001; 33(6):1353-7. [PubMed: 11391522]

5. Everhart JE, Ruhl CE. Burden of digestive diseases in the United States Part III: liver, biliary tract, and pancreas. Gastroenterology. 2009; 136(4):1134-44. [PubMed: 19245868]

6. Khan SA, Emadossadaty S, Ladep NG, et al. Rising trends in cholangiocarcinoma: is the ICD classification system misleading us? J Hepatol. 2012; 56(4):848-54. [PubMed: 22173164]

7. Sempoux C, Jibara G, Ward SC, et al. Intrahepatic cholangiocarcinoma: new insights in pathology. Semin Liver Dis. 2011; 31(1):49-60. [PubMed: 21344350]

8. Altaee MY, Johnson PJ, Farrant JM, et al. Etiologic and clinical characteristics of peripheral and hilar cholangiocarcinoma. Cancer. 1991; 68(9):2051-5. [PubMed: 1717133]

9. Koh KC, Lee H, Choi MS, et al. Clinicopathologic features and prognosis of combined hepatocellular cholangiocarcinoma. Am J Surg. 2005; 189(1):120-5. [PubMed: 15701504]

10. Nathan H, Aloia TA, Vauthey JN, et al. A proposed staging system for intrahepatic cholangiocarcinoma. Ann Surg Oncol. 2009; 16(1):14-22. [PubMed: 18987916]

11. Patel T. Worldwide trends in mortality from biliary tract malignancies. BMC Cancer. 2002; 2:10. [PubMed: 11991810]

12. Yang J, Yan LN. Current status of intrahepatic cholangiocarcinoma. World J Gastroenterol. 2008; 14(41):6289-97. [PubMed: 19009641]

13. de Groen PC, Gores GJ, LaRusso NF, et al. Biliary tract cancers. N Engl J Med. 1999; 341(18): 1368-78. [PubMed: 10536130]

14. Dhanasekaran R, Hemming AW, Zendejas I, et al. Treatment outcomes and prognostic factors of intrahepatic cholangiocarcinoma. Oncol Rep. 2013; 29(4):1259-67. [PubMed: 23426976]

15. Yamasaki S. Intrahepatic cholangiocarcinoma: macroscopic type and stage classification. J Hepatobiliary Pancreat Surg. 2003; 10(4):288-91. [PubMed: 14598147]

16. Sasaki A, Aramaki M, Kawano K, et al. Intrahepatic peripheral cholangiocarcinoma: mode of spread and choice of surgical treatment. Br J Surg. 1998; 85(9):1206-9. [PubMed: 9752860]

17. Shimada K, Sano T, Sakamoto Y, et al. Surgical outcomes of the mass-forming plus periductal infiltrating types of intrahepatic cholangiocarcinoma: a comparative study with the typical massforming type of intrahepatic cholangiocarcinoma. World J Surg. 2007; 31(10):2016-22. [PubMed: 17687597]

18. Yamamoto J, Kosuge T, Takayama T, et al. Surgical treatment of intrahepatic cholangiocarcinoma: four patients surviving more than five years. Surgery. 1992; 111(6):617-22. [PubMed: 1317612]

19. de Jong MC, Nathan H, Sotiropoulos GC, et al. Intrahepatic cholangiocarcinoma: an international multi-institutional analysis of prognostic factors and lymph node assessment. J Clin Oncol. 2011; 29(23):3140-5. [PubMed: 21730269]

20. Suh KS, Roh HR, Koh YT, et al. Clinicopathologic features of the intraductal growth type of peripheral cholangiocarcinoma. Hepatology. 2000; 31(1):12-7. [PubMed: 10613721]

21. DeOliveira ML, Cunningham SC, Cameron JL, et al. Cholangiocarcinoma: thirty-one-year experience with 564 patients at a single institution. Ann Surg. 2007; 245(5):755-62. [PubMed: 17457168]

22. Paik KY, Jung JC, Heo JS, et al. What prognostic factors are important for resected intrahepatic cholangiocarcinoma? J Gastroenterol Hepatol. 2008; 23(5):766-70. [PubMed: 17868336]

23. Endo I, Gonen M, Yopp AC, et al. Intrahepatic cholangiocarcinoma: rising frequency, improved survival, and determinants of outcome after resection. Ann Surg. 2008; 248(1):84-96. [PubMed: 18580211] 
24. Blechacz B, Komuta M, Roskams T, et al. Clinical diagnosis and staging of cholangiocarcinoma. Nat Rev Gastroenterol Hepatol. 2011; 8(9):512-22. [PubMed: 21808282]

25. Shen WF, Zhong W, Xu F, et al. Clinicopathological and prognostic analysis of 429 patients with intrahepatic cholangiocarcinoma. World J Gastroenterol. 2009; 15(47):5976-82. [PubMed: 20014463]

26. Chen CY, Shiesh SC, Tsao HC, et al. The assessment of biliary CA 125, CA 19-9 and CEA in diagnosing cholangiocarcinoma-the influence of sampling time and hepatolithiasis. Hepatogastroenterology. 2002; 49(45):616-20. [PubMed: 12063953]

27. Mann DV, Edwards R, Ho S, et al. Elevated tumour marker CA19-9: clinical interpretation and influence of obstructive jaundice. Eur J Surg Oncol. 2000; 26(5):474-9. [PubMed: 11016469]

28. Nichols JC, Gores GJ, LaRusso NF, et al. Diagnostic role of serum CA 19-9 for cholangiocarcinoma in patients with primary sclerosing cholangitis. Mayo Clin Proc. 1993; 68(9): 874-9. [PubMed: 8396700]

29. Miller G, Schwartz LH, D'Angelica M. The use of imaging in the diagnosis and staging of hepatobiliary malignancies. Surg Oncol Clin N Am. 2007; 16(2):343-68. [PubMed: 17560517]

30. Wibulpolprasert B, Dhiensiri T. Peripheral cholangiocarcinoma: sonographic evaluation. J Clin Ultrasound. 1992; 20(5):303-14. [PubMed: 1316372]

31. Colli A, Cocciolo M, Mumoli N, et al. Peripheral intrahepatic cholangiocarcinoma: ultrasound findings and differential diagnosis from hepatocellular carcinoma. Eur J Ultrasound. 1998; 7(2): 93-9. [PubMed: 9614277]

32. Zhang Y, Uchida M, Abe T, et al. Intrahepatic peripheral cholangiocarcinoma: comparison of dynamic CT and dynamic MRI. J Comput Assist Tomogr. 1999; 23(5):670-7. [PubMed: 10524843]

33. Kim TK, Choi BI, Han JK, et al. Peripheral cholangiocarcinoma of the liver: two-phase spiral CT findings. Radiology. 1997; 204(2):539-43. [PubMed: 9240550]

34. Asayama Y, Yoshimitsu K, Irie H, et al. Delayed-phase dynamic CT enhancement as a prognostic factor for mass-forming intrahepatic cholangiocarcinoma. Radiology. 2006; 238(1):150-5. [PubMed: 16304089]

35. Anderson CD, Rice MH, Pinson CW, et al. Fluorodeoxyglucose PET imaging in the evaluation of gallbladder carcinoma and cholangiocarcinoma. J Gastrointest Surg. 2004; 8(1):90-7. [PubMed: 14746840]

36. Kim YJ, Yun M, Lee WJ, et al. Usefulness of 18F-FDG PET in intrahepatic cholangiocarcinoma. Eur J Nucl Med Mol Imaging. 2003; 30(11):1467-72. [PubMed: 14579085]

37. Fevery J, Buchel O, Nevens F, et al. Positron emission tomography is not a reliable method for the early diagnosis of cholangiocarcinoma in patients with primary sclerosing cholangitis. J Hepatol. 2005; 43(2):358-60. [PubMed: 15975687]

38. Fritscher-Ravens A, Bohuslavizki KH, Broering DC, et al. FDG PET in the diagnosis of hilar cholangiocarcinoma. Nucl Med Commun. 2001; 22(12):1277-85. [PubMed: 11711897]

39. Andersen JB, Spee B, Blechacz BR, et al. Genomic and genetic characterization of cholangiocarcinoma identifies therapeutic targets for tyrosine kinase inhibitors. Gastroenterology. 2012; 142(4):1021-31. e15. [PubMed: 22178589]

40. Sia D, Hoshida Y, Villanueva A, et al. Integrative molecular analysis of intrahepatic cholangiocarcinoma reveals 2 classes that have different outcomes. Gastroenterology. 2013; 144(4):829-40. [PubMed: 23295441]

41. Edge SB, Compton CC. The American Joint Committee on Cancer: the 7th edition of the AJCC cancer staging manual and the future of TNM. Ann Surg Oncol. 2010; 17(6):1471-4. [PubMed: 20180029]

42. Farges O, Fuks D, Le Treut YP, et al. AJCC 7th edition of TNM staging accurately discriminates outcomes of patients with resectable intrahepatic cholangiocarcinoma: by the AFC-IHCC-2009 study group. Cancer. 2011; 117(10):2170-7. [PubMed: 21523730]

43. Igami T, Ebata T, Yokoyama Y, et al. Staging of peripheral-type intrahepatic cholangiocarcinoma: appraisal of the new TNM classification and its modifications. World J Surg. 2011; 35(11):25019. [PubMed: 21879422] 
44. Wang Y, Li J, Xia Y, et al. Prognostic nomogram for intrahepatic cholangiocarcinoma after partial hepatectomy. J Clin Oncol. 2013; 31(9):1188-95. [PubMed: 23358969]

45. Nakeeb A, Pitt HA, Sohn TA, et al. Cholangiocarcinoma. A spectrum of intrahepatic, perihilar, and distal tumors. Ann Surg. 1996; 224(4):463-73. discussion: 473-5. [PubMed: 8857851]

46. Morise Z, Sugioka A, Tokoro T, et al. Surgery and chemotherapy for intrahepatic cholangiocarcinoma. World J Hepatol. 2010; 2(2):58-64. [PubMed: 21160974]

47. Vauthey JN, Chaoui A, Do KA, et al. Standardized measurement of the future liver remnant prior to extended liver resection: methodology and clinical associations. Surgery. 2000; 127(5):512-9. [PubMed: 10819059]

48. Abdalla EK, Barnett CC, Doherty D, et al. Extended hepatectomy in patients with hepatobiliary malignancies with and without preoperative portal vein embolization. Arch Surg. 2002; 137(6): 675-80. discussion: 680-1. [PubMed: 12049538]

49. Kishi Y, Abdalla EK, Chun YS, et al. Three hundred and one consecutive extended right hepatectomies: evaluation of outcome based on systematic liver volumetry. Ann Surg. 2009; 250(4):540-8. [PubMed: 19730239]

50. Ebata T, Yokoyama Y, Igami T, et al. Portal vein embolization before extended hepatectomy for biliary cancer: current technique and review of 494 consecutive embolizations. Dig Surg. 2012; 29(1):23-9. [PubMed: 22441616]

51. Hemming AW, Reed AI, Howard RJ, et al. Preoperative portal vein embolization for extended hepatectomy. Ann Surg. 2003; 237(5):686-91. discussion: 691-3. [PubMed: 12724635]

52. Weber SM, Jarnagin WR, Klimstra D, et al. Intrahepatic cholangiocarcinoma: resectability, recurrence pattern, and outcomes. J Am Coll Surg. 2001; 193(4):384-91. [PubMed: 11584966]

53. Goere D, Wagholikar GD, Pessaux P, et al. Utility of staging laparoscopy in subsets of biliary cancers: laparoscopy is a powerful diagnostic tool in patients with intrahepatic and gallbladder carcinoma. Surg Endosc. 2006; 20(5):721-5. [PubMed: 16508808]

54. Aloia TA, Fahy BN, Fischer CP, et al. Predicting poor outcome following hepatectomy: analysis of 2313 hepatectomies in the NSQIP database. HPB (Oxford). 2009; 11(6):510-5. [PubMed: 19816616]

55. Ali SM, Clark CJ, Zaydfudim VM, et al. Role of major vascular resection in patients with intrahepatic cholangiocarcinoma. Ann Surg Oncol. 2012; 20(6):2023-8. [PubMed: 23263702]

56. Guglielmi A, Ruzzenente A, Campagnaro T, et al. Intrahepatic cholangiocarcinoma: prognostic factors after surgical resection. World J Surg. 2009; 33(6):1247-54. [PubMed: 19294467]

57. Konstadoulakis MM, Roayaie S, Gomatos IP, et al. Fifteen-year, single-center experience with the surgical management of intrahepatic cholangiocarcinoma: operative results and long-term outcome. Surgery. 2008; 143(3):366-74. [PubMed: 18291258]

58. Madariaga JR, Iwatsuki S, Todo S, et al. Liver resection for hilar and peripheral cholangiocarcinomas: a study of 62 cases. Ann Surg. 1998; 227(1):70-9. [PubMed: 9445113]

59. Lang H, Sotiropoulos GC, Sgourakis G, et al. Operations for intrahepatic cholangiocarcinoma: single-institution experience of 158 patients. J Am Coll Surg. 2009; 208(2):218-28. [PubMed: 19228533]

60. Farges O, Fuks D, Boleslawski E, et al. Influence of surgical margins on outcome in patients with intrahepatic cholangiocarcinoma: a multicenter study by the AFC-IHCC-2009 study group. Ann Surg. 2011; 254(5):824-9. discussion: 830. [PubMed: 22042474]

61. Nakagawa T, Kamiyama T, Kurauchi N, et al. Number of lymph node metastases is a significant prognostic factor in intrahepatic cholangiocarcinoma. World J Surg. 2005; 29(6):728-33. [PubMed: 15880276]

62. Nathan H, Pawlik TM, Wolfgang CL, et al. Trends in survival after surgery for cholangiocarcinoma: a 30-year population-based SEER database analysis. J Gastrointest Surg. 2007; 11(11):1488-96. discussion: 1496-7. [PubMed: 17805937]

63. Shirabe K, Shimada M, Harimoto N, et al. Intrahepatic cholangiocarcinoma: its mode of spreading and therapeutic modalities. Surgery. 2002; 131(Suppl 1):S159-64. [PubMed: 11821804]

64. Okami J, Dono K, Sakon M, et al. Patterns of regional lymph node involvement in intrahepatic cholangiocarcinoma of the left lobe. J Gastrointest Surg. 2003; 7(7):850-6. [PubMed: 14592657] 
65. Morine Y, Shimada M, Utsunomiya T, et al. Clinical impact of lymph node dissection in surgery for peripheral-type intrahepatic cholangiocarcinoma. Surg Today. 2012; 42(2):147-51. [PubMed: 22124809]

66. Nguyen KT, Steel J, Vanounou T, et al. Initial presentation and management of hilar and peripheral cholangiocarcinoma: is a node-positive status or potential margin-positive result a contraindication to resection? Ann Surg Oncol. 2009; 16(12):3308-15. [PubMed: 19774418]

67. Reddy SK, Tsung A, Geller DA. Laparoscopic liver resection. World J Surg. 2011; 35(7):1478-86. [PubMed: 21181472]

68. Koffron AJ, Auffenberg G, Kung R, et al. Evaluation of 300 minimally invasive liver resections at a single institution: less is more. Ann Surg. 2007; 246(3):385-92. discussion: 392-4. [PubMed: 17717442]

69. Buell JF, Thomas MJ, Doty TC, et al. An initial experience and evolution of laparoscopic hepatic resectional surgery. Surgery. 2004; 136(4):804-11. [PubMed: 15467665]

70. Ito K, Ito H, Are C, et al. Laparoscopic versus open liver resection: a matched-pair case control study. J Gastrointest Surg. 2009; 13(12):2276-83. [PubMed: 19727974]

71. Tsinberg M, Tellioglu G, Simpfendorfer CH, et al. Comparison of laparoscopic versus open liver tumor resection: a case-controlled study. Surg Endosc. 2009; 23(4):847-53. [PubMed: 19116739]

72. Sarpel U, Hefti MM, Wisnievsky JP, et al. Outcome for patients treated with laparoscopic versus open resection of hepatocellular carcinoma: case-matched analysis. Ann Surg Oncol. 2009; 16(6): 1572-7. [PubMed: 19259738]

73. Packiam V, Bartlett DL, Tohme S, et al. Minimally invasive liver resection: robotic versus laparoscopic left lateral sectionectomy. J Gastrointest Surg. 2012; 16(12):2233-8. [PubMed: 23054901]

74. Choi GH, Choi SH, Kim SH, et al. Robotic liver resection: technique and results of 30 consecutive procedures. Surg Endosc. 2012; 26(8):2247-58. [PubMed: 22311301]

75. Kitisin K, Packiam V, Bartlett DL, et al. A current update on the evolution of robotic liver surgery. Minerva Chir. 2011; 66(4):281-93. [PubMed: 21873962]

76. Casavilla FA, Marsh JW, Iwatsuki S, et al. Hepatic resection and transplantation for peripheral cholangiocarcinoma. J Am Coll Surg. 1997; 185(5):429-36. [PubMed: 9358085]

77. Goldstein RM, Stone M, Tillery GW, et al. Is liver transplantation indicated for cholangiocarcinoma? Am J Surg. 1993; 166(6):768-71. discussion: 771-2. [PubMed: 8273866]

78. Ghali P, Marotta PJ, Yoshida EM, et al. Liver transplantation for incidental cholangiocarcinoma: analysis of the Canadian experience. Liver Transpl. 2005; 11(11):1412-6. [PubMed: 16237695]

79. Meyer CG, Penn I, James L. Liver transplantation for cholangiocarcinoma: results in 207 patients. Transplantation. 2000; 69(8):1633-7. [PubMed: 10836374]

80. Hong JC, Jones CM, Duffy JP, et al. Comparative analysis of resection and liver transplantation for intrahepatic and hilar cholangiocarcinoma: a 24-year experience in a single center. Arch Surg. 2011; 146(6):683-9. [PubMed: 21690444]

81. Becker NS, Rodriguez JA, Barshes NR, et al. Outcomes analysis for 280 patients with cholangiocarcinoma treated with liver transplantation over an 18-year period. J Gastrointest Surg. 2008; 12(1):117-22. [PubMed: 17963015]

82. Gores GJ, Darwish Murad S, Heimbach JK, et al. Liver transplantation for perihilar cholangiocarcinoma. Dig Dis. 2013; 31(1):126-9. [PubMed: 23797134]

83. Valle J, Wasan H, Palmer DH, et al. Cisplatin plus gemcitabine versus gemcitabine for biliary tract cancer. N Engl J Med. 2010; 362(14):1273-81. [PubMed: 20375404]

84. Shinohara ET, Mitra N, Guo M, et al. Radiation therapy is associated with improved survival in the adjuvant and definitive treatment of intrahepatic cholangiocarcinoma. Int J Radiat Oncol Biol Phys. 2008; 72(5):1495-501. [PubMed: 18472359]

85. Vogl TJ, Naguib NN, Nour-Eldin NE, et al. Transarterial chemoembolization in the treatment of patients with unresectable cholangiocarcinoma: results and prognostic factors governing treatment success. Int J Cancer. 2012; 131(3):733-40. [PubMed: 21976289]

86. Park SY, Kim JH, Yoon HJ, et al. Transarterial chemoembolization versus supportive therapy in the palliative treatment of unresectable intrahepatic cholangiocarcinoma. Clin Radiol. 2011; 66(4): 322-8. [PubMed: 21356394] 
87. Gusani NJ, Balaa FK, Steel JL, et al. Treatment of unresectable cholangiocarcinoma with gemcitabine-based transcatheter arterial chemoembolization (TACE): a single-institution experience. J Gastrointest Surg. 2008; 12(1):129-37. [PubMed: 17851723]

88. Shen WF, Zhong W, Liu Q, et al. Adjuvant transcatheter arterial chemoembolization for intrahepatic cholangiocarcinoma after curative surgery: retrospective control study. World J Surg. 2011; 35(9):2083-91. [PubMed: 21698503] 


\section{KEY POINTS}

- Intrahepatic cholangiocarcinomas (ICCs) are aggressive, locally invasive tumors with limited 5-year survival. Multifocality, vascular invasion, lymphatic spread, and tumor histology are all determinants of staging and prognosis.

- Both the incidence and the mortality of ICCs have risen over the past several decades.

- Surgical resection is the only viable treatment option for patients who present with ICCs. Minimally invasive hepatectomy is increasingly becoming a valid option in select cases. 


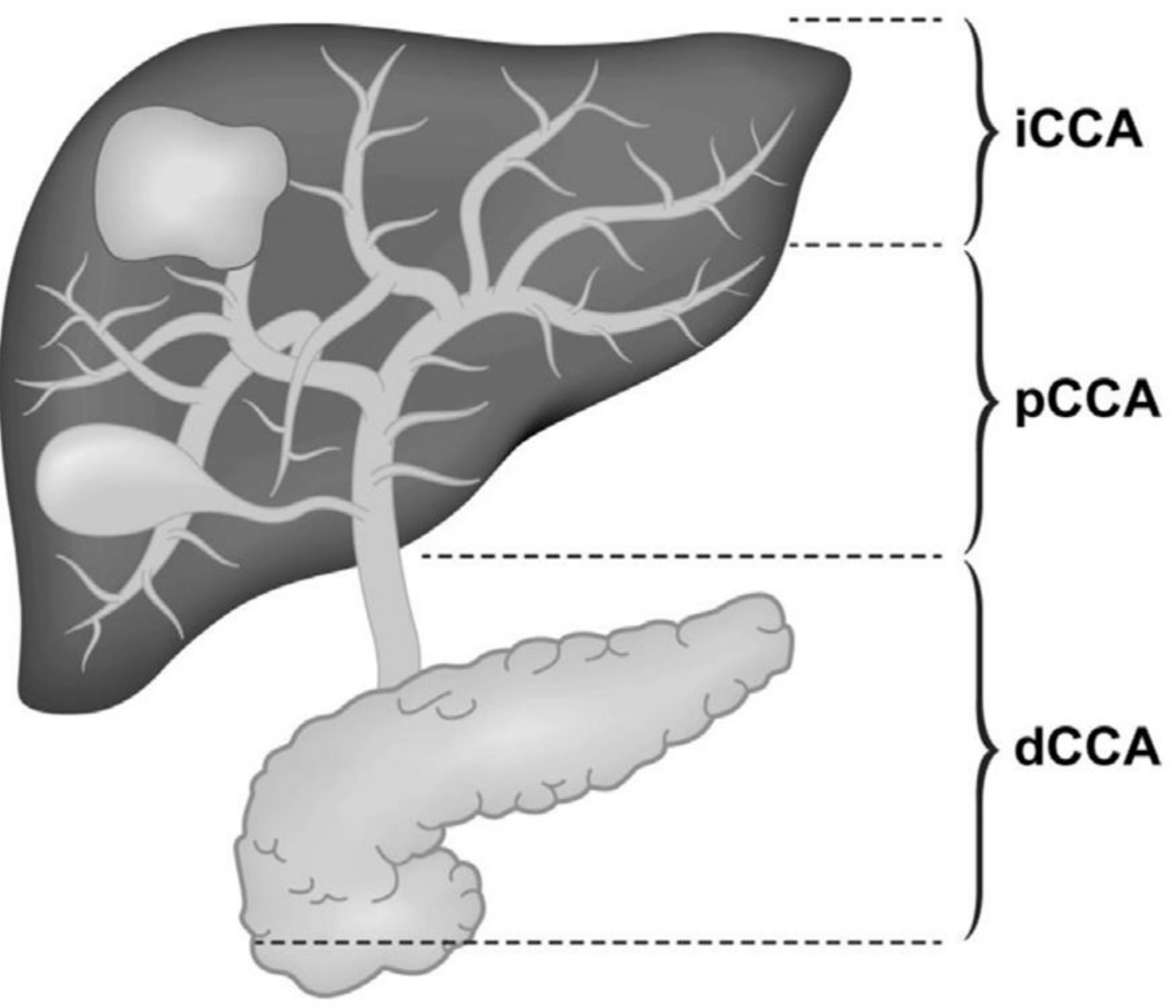

Fig. 1.

Anatomic distribution of cholangiocarcinomas. Intrahepatic lesions such as the lesion in the right lobe of the liver shown in this image are many times asymptomatic and as a result present at a later stage. dCCA, distal cholangiocarcinoma; iCCA, intrahepatic cholangiocarcinoma; pCCA, perihilar cholangiocarcinoma. 


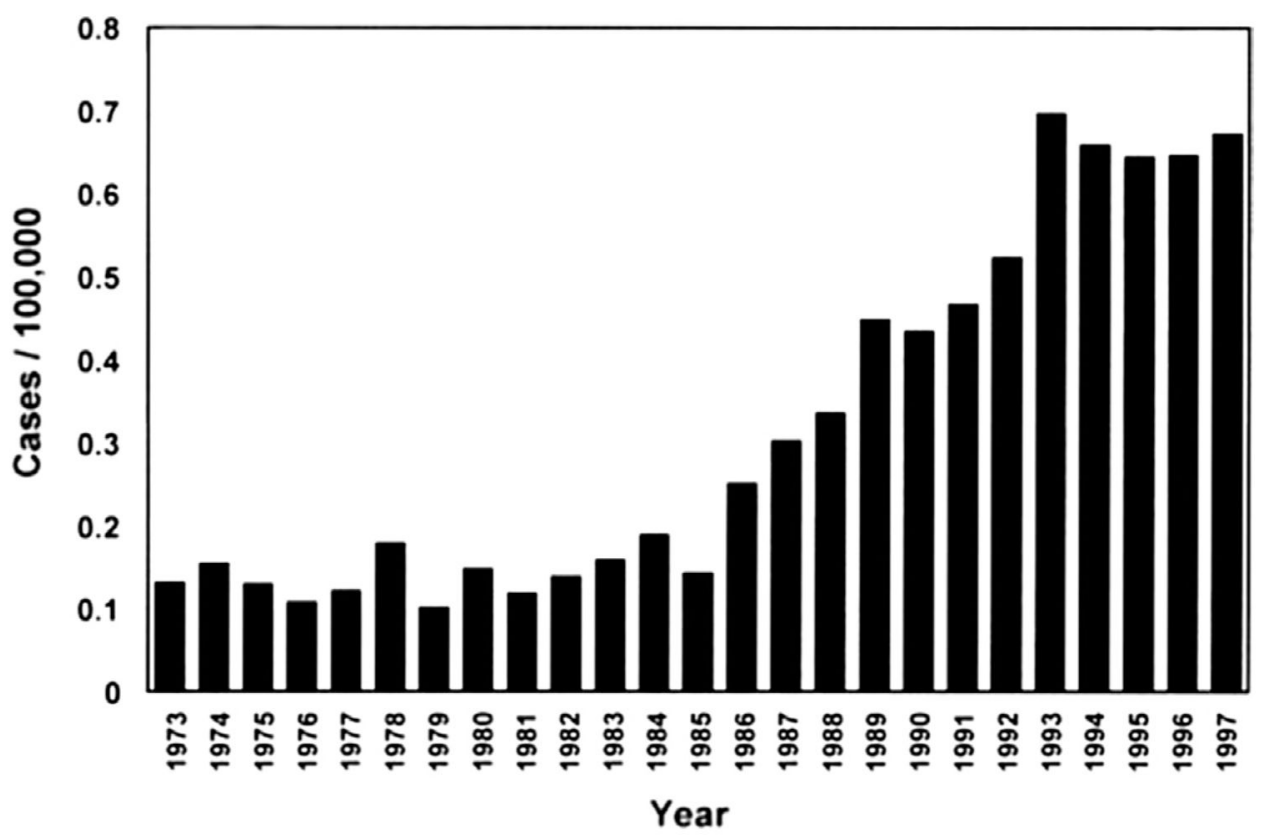

Fig. 2.

Age-adjusted mortality for ICC, 1973-1997. (From Patel T. Increasing incidence and mortality of primary intrahepatic cholangiocarcinoma in the United States. Hepatology 2001;33(6):1354; with permission.) 

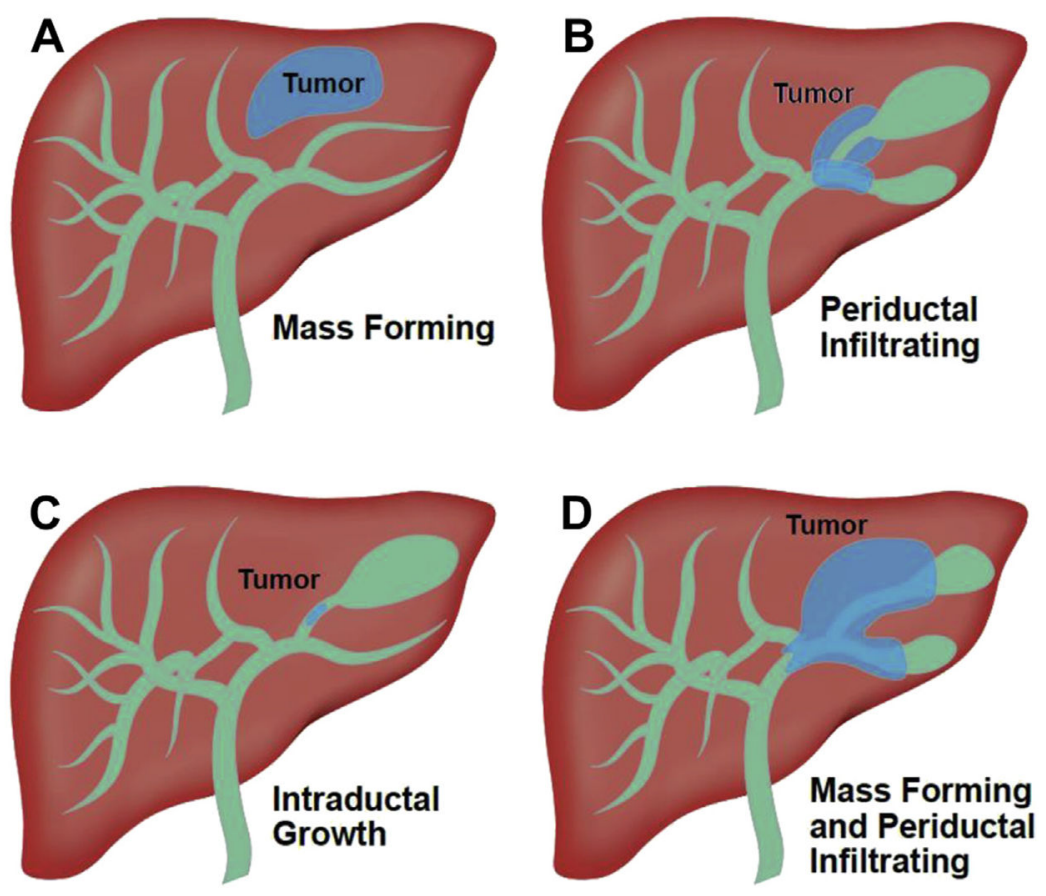

Fig. 3.

Histologic subtypes of ICC. Mass-forming types $(A)$ are the most common type, typically presenting as a mass lesion. Periductal infiltrating $(B)$ are the next most common and infiltrate the hepatic parenchyma along portal structures. Intraductal growth types $(C)$ carry the best prognosis but are the least common. Mass-forming periductal infiltrating mixed type $(D)$ have been suggested to be the most aggressive of these subtypes. 


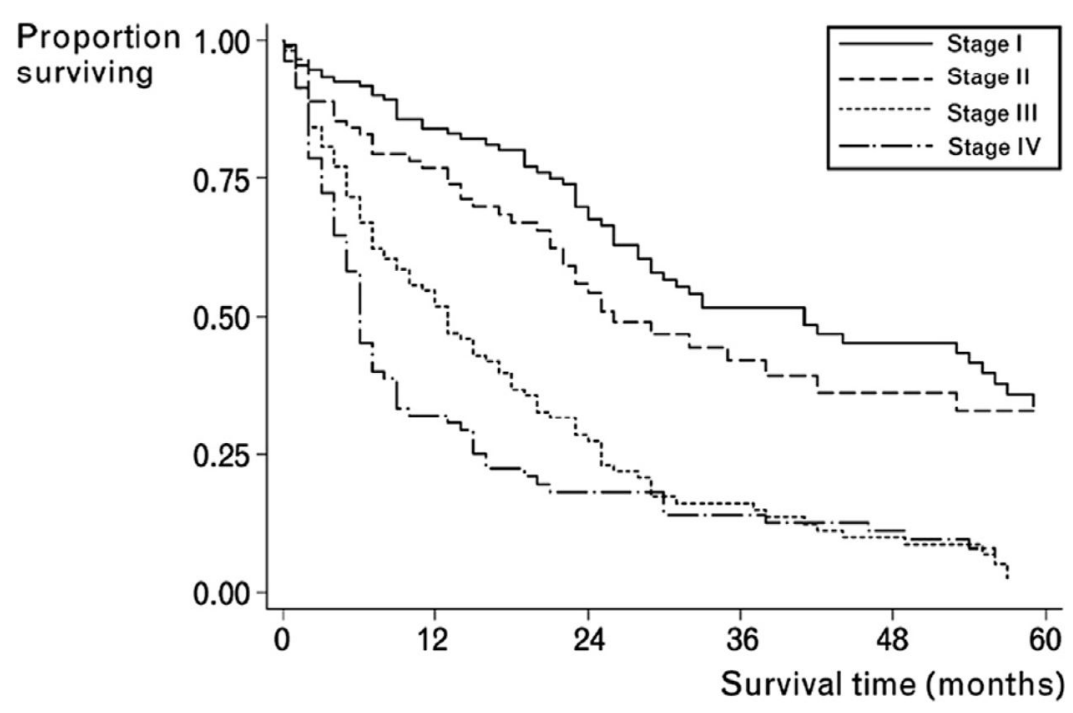

Fig. 4.

Kaplan-Meier survival curve of patients with cholangiocarcinoma. (From Nathan H, Pawlik TM. Staging of intrahepatic cholangiocarcinoma. Curr Opin Gastroenterol 2010;26(3):271; with permission.) 


\section{Table 1}

\section{Staging classification for intrahepatic cholangiocarcinoma}

\begin{tabular}{|c|c|}
\hline Classification & Description \\
\hline $\mathrm{T} 1$ & Solitary tumor without vascular invasion ${ }^{a}$ \\
\hline $\mathrm{T} 2 \mathrm{a}$ & Solitary tumor with vascular invasion ${ }^{a}$ \\
\hline $\mathrm{T} 2 \mathrm{~b}$ & Multiple tumors, with or without vascular invasion ${ }^{a}$ \\
\hline $\mathrm{T} 3$ & Tumor perforating visceral peritoneum or involving local extrahepatic structures by direct invasion \\
\hline $\mathrm{T} 4$ & Tumor with periductal invasion $b$ \\
\hline No & No regional lymph node metastasis \\
\hline N1 & Regional lymph node metastasis $c$ \\
\hline M0 & No distant metastasis \\
\hline M1 & Distant metastasis \\
\hline \multicolumn{2}{|l|}{ Stage groupings } \\
\hline Stage I & T1 N0 M0 \\
\hline Stage II & T2 N0 M0 \\
\hline Stage III & T3 N0 M0 \\
\hline Stage IVA & T4 N0 M0, any T N1 M0 \\
\hline Stage IVB & Any T, any N M1 \\
\hline
\end{tabular}

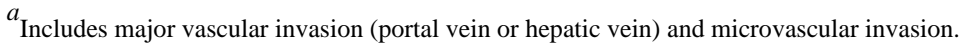

$b$

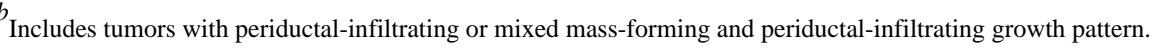

${ }^{c}$ Nodal involvement of the celiac, periaortic, or caval lymph nodes is considered to be distant metastasis (M1).

Adapted from Edge SB, Byrd DR, Compton CC, et al, editors. AJCC cancer staging manual. 7th edition. New York: Springer; 2010; with permission. 


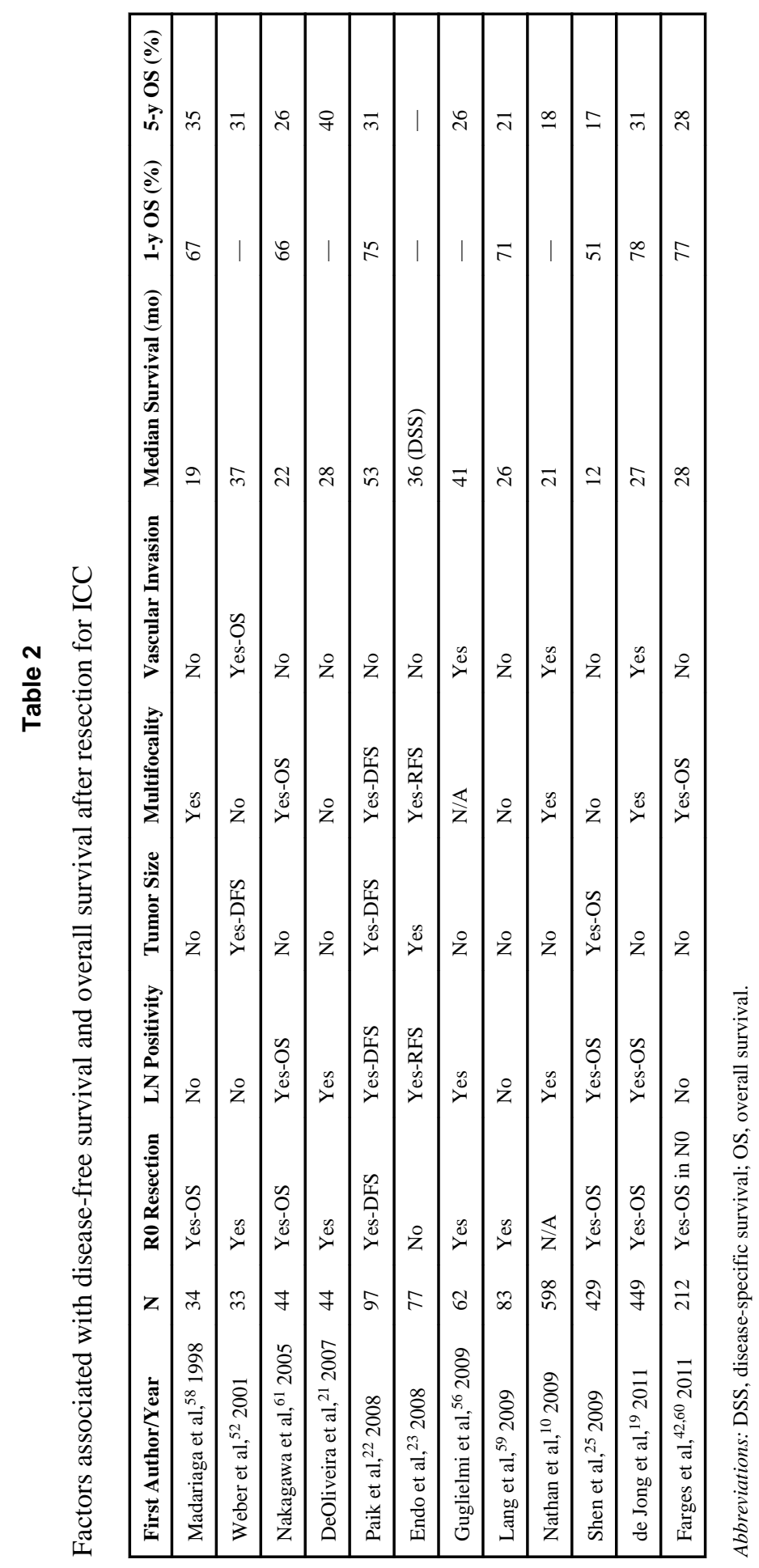

Surg Oncol Clin N Am. Author manuscript; available in PMC 2014 May 02. 